\title{
Technology Spillovers and Economic Vitality: An Analysis of Institutional Flexibility in Japan with Comparisons to the USA
}

Charla Griffy-Brown

Graziadio School of Business, Culver City, CA, USA

Akira Nagamatsu, Chihiro Watanabe

Tokyo Institute of Technology, Tokyo, Japan

Bing Zhu

International Institute for Applied Systems Analysis, Laxenburg, Austria

RR-03-03

March 2003

Reprinted from International Journal of Technology Management, 23(7/8):

746-768 (2002). 
Research Reports, which record research conducted at IIASA, are independently reviewed before publication. Views or opinions expressed herein do not necessarily represent those of the Institute, its National Member Organizations, or other organizations supporting the work.

Reprinted with permission from International Journal of Technology Management, 23(7/8):746-768 (2002).

Copyright (@) 2002 Inderscience Enterprises Ltd.

The International Journal of Technology Management is published in both print and electronic format. For more information visit their web site www. inderscience.com

All rights reserved. No part of this publication may be reproduced or transmitted in any form or by any means, electronic or mechanical, including photocopy, recording, or any information storage or retrieval system, without permission in writing from the copyright holder. 


\title{
Technology spillovers and economic vitality: an analysis of institutional flexibility in Japan with comparisons to the USA
}

\section{Charla Griffy-Brown}

Department of Decision and Information Systems, Graziadio School of Business, Pepperdine University Plaza, 400 Corporate Pointe, Culver City CA 90230, USA

E-mail: charla.brown@pepperdine.edu

\section{Akira Nagamatsu, Chihiro Watanabe and Bing Zhu}

Department of Management and Engineering, Tokyo Institute of Technology, Tokyo, Japan

E-mail: chihiro@me.titech.ac.jp

\begin{abstract}
In Japan, technology spillovers have been less successful in the 1990 s than they were in the 1980s. One apparent reason for this is a decline in institutional flexibility - the ability of organisations to absorb technology, transform human capital and adapt to changing global conditions. Information and communication technology (ICT) has become embedded in US business practice, but Japanese firms have yet to absorb ICT or respond to human capital needs. This lack of flexibility has had a significant negative impact on the vitality of the Japanese economy. Section 2 of this paper will demonstrate recent changes in Japan's institutional flexibility by contrasting technology spillovers of the 1970s and 80 s with those of the 1990s, linking this institutional flexibility with $R \& D$ diversification and showing the negative impact on Total Factor Productivity and GDP. This analysis was performed using data compiled by the Tokyo Institute of Technology as well as data from recent surveys conducted by a number of Japanese government offices and agencies. Section 2 will also discuss Japan's 'dual economy' by looking at key differences between Small and Medium-sized Enterprises (SMEs) and Large Enterprises (LEs) in terms of labour rigidity and ICT penetration. These differences are one aspect of institutional flexibility. Section 3 starts by comparing the economic growth rates in Japan and the USA in the second part of the 1980s and the first part of the 1990s. A comparison of labour, capital, material and Total Factor Productivity indicates a decline in flexibility in Japan and an increase in flexibility in the USA. Additionally, this reversal can be seen in technology, labour and capital substitution. Section 4 discusses key changes in the US and Japanese organisational environments as they converge on different digital platforms and implications for their respective institutions. Key questions are raised regarding often over-simplified fundamental changes purported in the USA. In this regard, the truly 'innovative' nature of SMEs in the USA is questioned as institutional rigidity in this sector grows. Section 5 summarises final implications of this analysis and directs future work towards questions arising from this study.
\end{abstract}

Keywords: Technology spillovers; institutional elasticity; economic vitality; information technology; Japan; USA. 
Reference to this paper should be made as follows: Griffy-Brown, C., Nagamatsu, A., Watanabe, C. and Zhu, B. (2002) 'Technology spillovers and economic vitality: an analysis of institutional flexibility in Japan with comparisons to the USA', Int. J. Technology Management, Vol. 23, Nos. 7/8, pp.746-768.

Biographical notes: Charla Griffy-Brown is currently an Associate Professor at Pepperdine University, USA and a Visiting Fellow at Tokyo Institute of Technology. A former Fulbright Scholar, she graduated from Harvard University and has a $\mathrm{PhD}$ in Technology Management from Griffith University, Queensland, Australia. She has worked for NASA at the Kennedy Space Center and has also worked as a lecturer at the Centre for Technology Management, Griffith University teaching innovation management courses in Australia, Singapore, Indonesia, Malaysia and Japan. She is also currently the Director of the Center for Innovative Business Resources at the Graziadio School of Business and Management, Pepperdine University.

Akira Nagamatsu is a $\mathrm{PhD}$ candidate at the Department of Industrial
Engineering and Management of Tokyo Institute of Technology (TIT). After
graduating from Yokohama Municipal University with a Masters Degree
(Industrial Management) he joined TIT undertaking techno-economic research.
He has been conducting research focusing on the elucidation of the firm's
innovation mechanism.

Chihiro Watanabe graduated from Tokyo University with a bachelor's degree in engineering (urban planning) in 1968 and received his $\mathrm{PhD}$ (arts and science) in 1992, also from Tokyo University. He began his affiliation with the Ministry of International Trade and Industry (MTT) in 1968. He is a former Deputy Director-General of Technology Development at MITI. He is currently Professor at the Department of Industrial Engineering and Management, Tokyo Institute of Technology and also Senior Advisor to the Director on Technology at the International Institute for Applied Systems Analysis (IIASA).

Bing Zhu graduated from Tsinghua University, Beijing, China with a bachelor's degree in engineering (Chemical Engineering) in 1990 and received his master's degree (engineering) in 1995, also from Tsinghua University. $\mathrm{He}$ was formally a lecturer at the Department of Chemical Engineering, Tsinghua University. He has been a research assistant at the International Institute for Applied Systems Analysis (IIASA). He recently completed his $\mathrm{PhD}$ at the Department of Industrial Engineering and Management, Tokyo Institute of Technology.

\section{Introduction}

At the beginning of the 21st century, firms of all sizes, from giants to start-ups, are scrambling to ascertain how to leverage information and communications technology (ICT) to enhance business practice. Increasingly, this issue is a strategic national concern as governments struggle with maximising domestic potential for absorbing and utilising these technologies [1-3]. Of particular interest is facilitating technology spillover, or the seemingly natural flow of technology, particularly ICT, across industries and within industry sectors $[4,5]$. In this context, this analysis will examine institutional flexibility in 
the two largest economies as a primary mechanism linked to technology spillover that enhances production.

The US and Japanese economies are highly interdependent $[1,6]$. Furthermore, both have been highly scrutinised in detail over the last half-century with respect to structural changes and fundamental differences [6-8]. In addition, other analyses have examined ICT penetration in the two economies [9-11]. However, the linkages between technology spillover and institutional elasticity have not been explored. Since the Asian economic crisis, keen observers have noted the critical role played by institutional gaps in the events that unfolded [12-15]. In particular, these works have shown that in East Asia, there has been a compression of economic development over two to three decades which took Europe more than a century to achieve. However, as these economies become locked into the global economic system, their economic institutions became subject to global pressures and standards [12]. Sometimes this resulted in mismatches between existing economic systems and institutions with the rapidly expanding and changing domestic markets of the 1990s. Furthermore, these mismatches arose from domestic economic institutions that were not commensurate with domestic political and social institutions. One major reason for this is that domestic political and social institutions are governed more by local rather than global pressures [12]. Thus, there exist institutional gaps. Similarly, Japan has compressed development into a few decades, yet the institutional consequences of this compressed development remain unexplored. This analysis will show that institutional flexibility is critical for technology spillovers and essential for sustainable strategic advantage. In other words, the ability to enhance production processes continuously depends on how institutions respond and adapt to changes, incorporating new labour and technology streams. Furthermore, the shifts indicated are related to technology spillovers and labour.

Both the USA and Japan have levels of institutional elasticity that have varied over time. For example, during the Meiji period, Japan's institutions were elastic enough to accommodate tremendous change both economically and socially as it opened to trade with the West [16]. However, these institutions became very inflexible during the 1930s but, following World War II, they demonstrated tremendous elasticity in absorbing technology and providing the foundation for economic development. The USA has demonstrated similar 'waves' of elasticity over the past century most recently during the economic struggles of the 1980 s where institutions had to become flexible in order to remain competitive, adopting new strategies (such as JT) and new technologies. In this regard, technology spillovers are a proxy for flexibility [17-19]. They demonstrate at the institutional level the capacity to absorb and assimilate new ideas and tools.

This work will demonstrate that, in Japan, technology spillovers were successful in the 1980 s but this capacity changed during the 1990s. Consequently, the difficulties in rejuvenating the Japanese economy are critically related to the capacity firms have for flexibly adjusting to changing global conditions. Furthermore, this flexibility is a function of a firm's ability to assimilate technology spillovers. This analysis will also suggest that this institutional flexibility has allowed ICTs to become embedded in US business practice throughout the 1990 s, but the current trend is that institutions are becoming more rigid as processes and technology become more standardised and embedded. Section 2 will demonstrate key changes in Japan's institutional flexibility by contrasting the 1970 s and 1980s with the 1990s in terms of technology spillovers, linking this institutional flexibility with R\&D diversification and showing the negative impact on Total Factor Productivity and GDP. Further support for this institutional trend will be demonstrated in 
the substitution of technology for labour. This analysis was performed using data compiled by the Tokyo Institute of Technology as well as data from recent surveys conducted by a number of Japanese government offices and agencies. Section 2 will also discuss Japan's 'dual economy' by looking at key differences between Small and Medium-sized Enterprises (SMEs) and Large Enterprises (LEs) in terms of Labour rigidity and ICT penetration. This part of the analysis will show that institutional flexibility is a key component of challenges faced in the so-called 'dual economy.' Section 3 starts by comparing the economic growth rate in Japan and the USA in the second part of the 1980s and the first part of the 1990s showing that there was a reversal of fortunes comparing labour, capital, material and Total Factor Productivity. Additionally, this reversal can be seen in technology, labour and capital substitution. The issue of organisational change in the USA versus Japan is addressed in Section 4. This section discusses key changes in US and Japanese organisational environments as they converge on different digital platforms. Key questions are raised regarding often oversimplified fundamental changes purported in the USA. In this regard, the truly 'innovative' nature of SMEs is questioned. Section 5 summarises final implications of this analysis and directs future work towards questions arising from this study with respect to strategic national decisions and sustainable competitive advantage at the firm level.

\section{Technology spillovers and key changes in Japan's institutional flexibility}

\subsection{The correlation between economic decline and $R \& D$ diversification in Japan}

Previous work has demonstrated the relationship between a firm's R\&D investment, scale of production, $R \& D$ investment conditions and external shocks in the Japanese economy $[18,20]$. These studies demonstrated that a firm's R\&D investment level is also governed by the level of maturity in the sector to which the firm belongs and subsequent state of the competitiveness of the sector [21]. An important point discussed in this body of literature is the interdependence of the firms and industry sectors involved. Given this mutual interdependence, the structural correlation between R\&D investment level, diversification of R\&D 'objects' (or objectives), technology spillover, TFP growth and subsequent production growth play a critical role in firms' $R \& D$ investments.

Figure 1 illustrates trends in R\&D investment and the ratio of the diversification of R\&D in major sectors of the Japanese manufacturing industry over the period 1970-1995. It is generally observed that Japan's manufacturing industry's vigorous R\&D activities remained competitive by diversifying its $R \& D$ 'objects' or focuses and that this effort at diversification decreased as R\&D stagnated due to the bursting of the bubble economy. This is an example of firms increasing their flexibility. Figure 1 demonstrates this behaviour in the manufacturing industry and suggests equation (1), which indicates that the diversification ratio of $R \& D$ objectives can be a function of the level of $R \& D$ investment. 
Figure 1 Trends in R\&D investment and the ratio of the diversification of R\&D 'objects' in major sectors of the Japanese manufacturing industry (1970-1995)
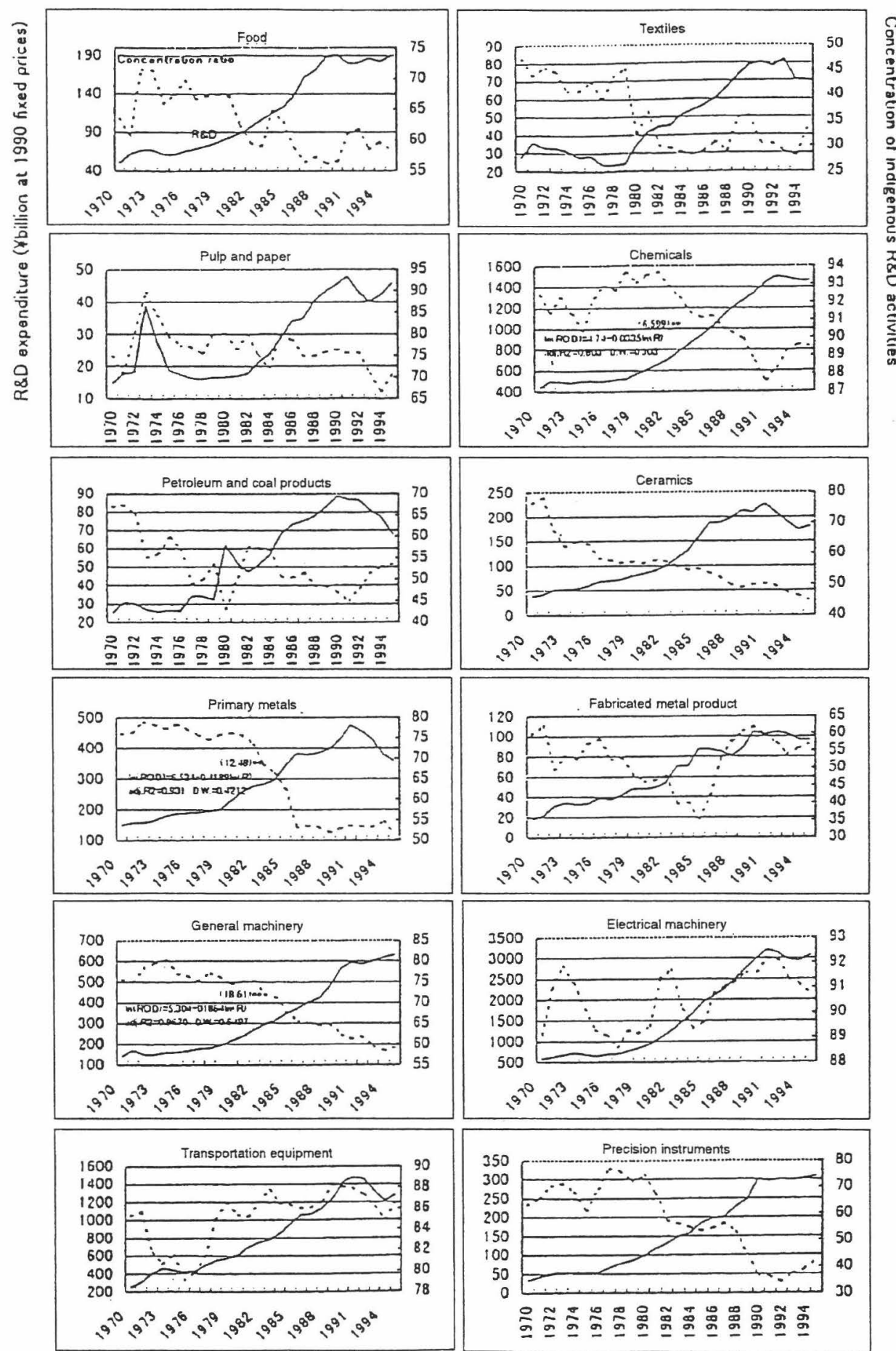


$$
\frac{R_{i i}}{R_{i}}=1-\sum_{j} \frac{R_{i j}}{R_{i}}=G\left(R_{i}\right)
$$

where $R_{i}:$ R\&D investment in sector $\mathrm{i} ; R_{i j}$ : sector $\mathrm{i} \& \mathrm{R}$ investment with field $\mathrm{j}$ R\&D objectives; $\sum_{j} \frac{R_{i j}}{R_{i}}$ : diversification ratio of sector $\mathrm{i}$.

This diversification of R\&D objectives postulates a concept of technology distance between sector $\mathrm{i}$ and $\mathrm{j}\left(P_{i j}\right)$ as indicated in equation (2), which indicates a degree of mutual technology dependency between two sectors (as distance becomes shorter the mutual technology dependence becomes weaker).

$$
P_{i j}=\frac{\sum\left(\frac{R_{i j}}{R_{i}}\right)\left(\frac{R_{j i}}{R_{j}}\right)}{\left[\sum\left(\frac{R_{i j}}{R_{i}}\right)^{2} \cdot \sum\left(\frac{R_{j i}}{R_{j}}\right)^{2}\right]^{1 / 2}}
$$

Technology distance inevitably provides a significant impact on the spillover of technology from sector $\mathrm{j}$ to sector $\mathrm{i}\left(\left[R_{i}\right]_{\mathrm{j}}\right)$ as indicated in equation (3).

$$
\left(\left[R_{i}\right]_{\mathrm{j}}=R_{j} \bullet P_{i j}\right.
$$

This technology spillover, similar to R\&D intensity, contributes to an increase in TFP as indicated in equation (3).

$$
\frac{\Delta T F P}{T F P}=\lambda+\frac{\partial Y_{i}}{\partial T_{i}} \bullet \frac{R_{i}}{Y_{i}}+\frac{\partial Y_{j}}{\partial T_{j}} \bullet \frac{\left[R_{i}\right]_{j}}{Y_{j}}
$$

The TFP increase contributes to production increase as indicated in equation (5).

$$
\frac{\Delta Y}{Y}=\sum \frac{\partial Y}{\partial X_{i}} \bullet \frac{\Delta X_{i}}{X_{i}}+\frac{\Delta T F P}{T F P}
$$

Increased production, together with $R \& D$ intensity, contributes to an increase in $R \& D$ investment as indicated in equation (6).

$$
\Delta R / R=\Delta(R / Y) /(R / Y)+Y / Y
$$

This increase in $R \& D$ investment again stimulates diversification in $R \& D$ objectives or 'objects' which makes technology distance longer (making the mutual interdependence stronger) catalysing more technology spillover as indicated in equations (1), (2) and (3).

These equations suggest a structural correlation between $R \& D$ investment level, diversification of R\&D, technology spillover, TFP growth and subsequently production growth and the next level of R\&D investment. Furthermore, this mutually reinforcing cycle requires a great deal of institutional flexibility in order for the diversification process to continue and for new technologies to be created and absorbed. However, in an adverse economic environment, this cycle changes as firms become more focused and rigid in order to cut costs and remain competitive. The problem is that this rigidity 
eventually erodes their competitive base. Other details that demonstrate this institutional rigidity such as the immutability of the labour force will be discussed in greater detail later in this section. However, before looking at these other issues, we will examine the implications of the mathematical relationships defined more carefully using empirical data from Japan's manufacturing sector.

Figure 2 indicates that technology distances between major industrial sectors and sectors with close interdependencies become shorter (mutual interdependencies became weaker) after the bursting of the bubble economy, which started in 1991 in the Japanese manufacturing industry. As indicated in equation (3), this weakening trend inevitably results in a stagnation of technology spillover. Figure 2 also demonstrates this stagnation in the Japanese manufacturing industry. Equation (4) provides a warning that this stagnation in technology spillover inevitably decreases TFP growth. Figure 3, which analyses the sources of the decreasing trends in TFP in the Japanese manufacturing industry, clearly demonstrates that the decrease in technology spillover was among the major sources of TFP decrease. Furthermore, as indicated in equation (5), the TFP decrease results in a production decrease. Figure 4 demonstrates a production decrease in the period after the bursting of the bubble economy. Finally, a production decrease inevitably results in a decrease in R\&D investment as indicated in equation (6). Figure 5 demonstrates that a dramatic decrease in R\&D investment in the Japanese manufacturing industry after the bursting of the bubble economy was largely due to a decrease in production. A decrease in $R \& D$ investment again stagnates diversification of $R \& D$ resulting in a stagnation of technology spillover. Stagnation of technology spillover again stagnates TFP growth resulting in the stagnation of growth and the succeeding R\&D investment breaking down into a 'vicious cycle'. At the core of this 'vicious cycle' is growing institutional 'rigidity.' As firms scale down, they lose their ability to respond and adapt to changes. As this flexibility is lost, it becomes more and more difficult for them to compete.

\subsection{Technology spillover and labour rigidity}

While this cycle may seem simple, it is in fact extremely complex, particularly as we consider the question of labour. Prior to this breakdown, Japan's sustainable post-war growth continued despite labour constraints. So, in terms of flexibility, how did Japan deal with these constraints prior to the 1990s in order to achieve such explosive growth during the 1970s and 1980s? A large body of literature has examined this question from the perspective of technology substitution for constrained production factors, particularly in the energy area [20,22]. As a result of these efforts, labour saving and automation facilities and technologies were developed and introduced broadly throughout Japan's manufacturing industry during the $1960 \mathrm{~s}, 70 \mathrm{~s}$ and $80 \mathrm{~s}$ [20]. However, the previous analysis suggests that this cycle, which coincides with technology spillover flexibility, is rather fragile, similar to an ecosystem. Once the cycle starts to breaks down, substitution of technology for labour becomes extremely difficult as the technology resources become more and more restricted. Furthermore, institutions no longer have the capacity to fill the gaps needed in the labour force if appropriate industry-university linkages are not there to fill this decline in resources or if the labour that exists is unable to fill the gaps in the changing economic dynamics. In other words, if the labour force is rigidly constructed to fit a specific 'mould' and perform certain skills with the expectation that technology will 
overcome labour constraints, once technology is not available to do this, the labour force does not have the flexibility to adapt to new business requirements. In this regard, Japan's 'dual economy' accounts for some of Japan's labour inflexibility.

Figure 2 Trends in technology distances (1985-1995) and technology spillover (1970-1994) in major sectors of the Japanese manufacturing industry
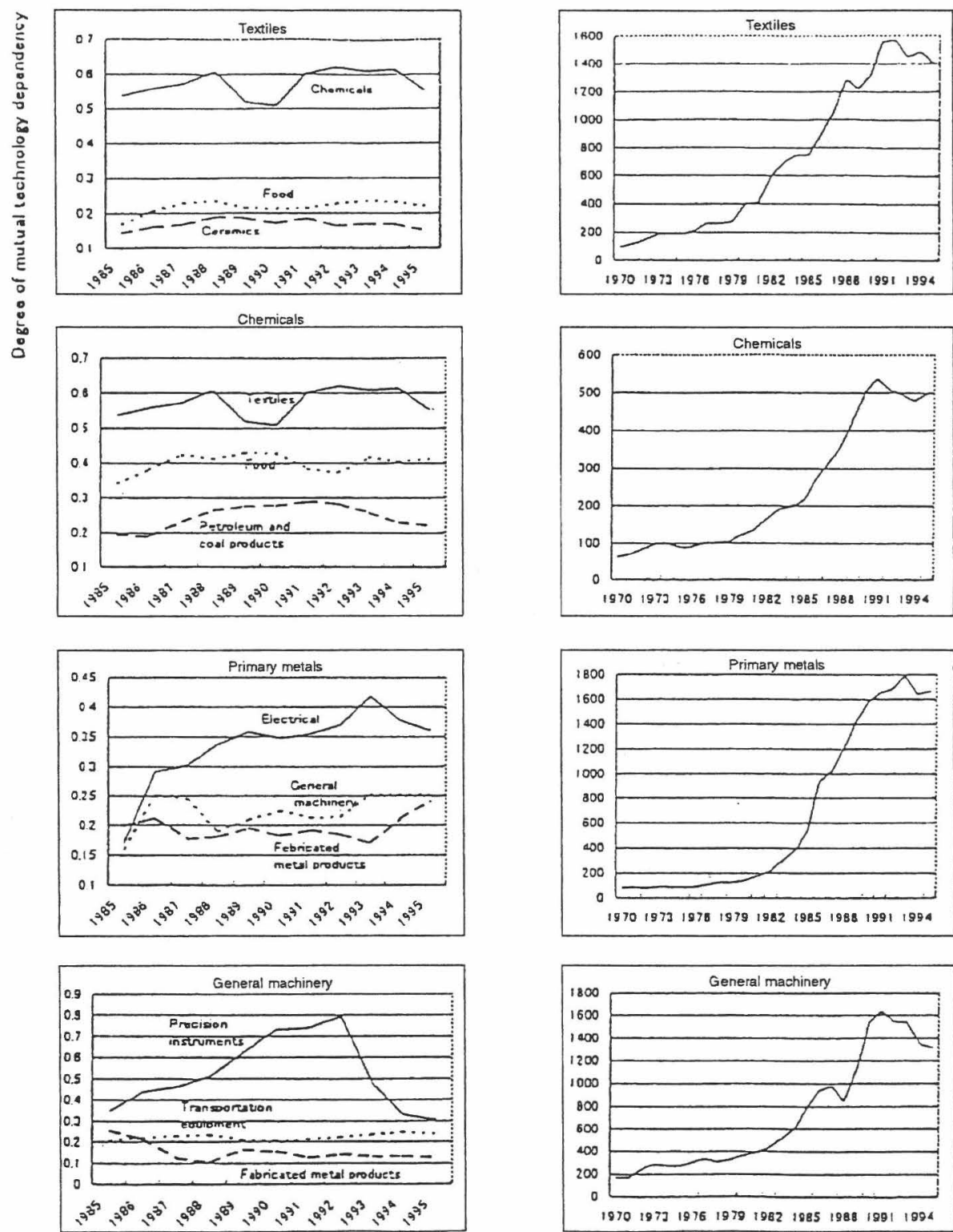

Technology Distances

Technology Spillover 
Figure 3 Factors contributing to change in TFP in the Japanese manufacturing industry (1980-1995)

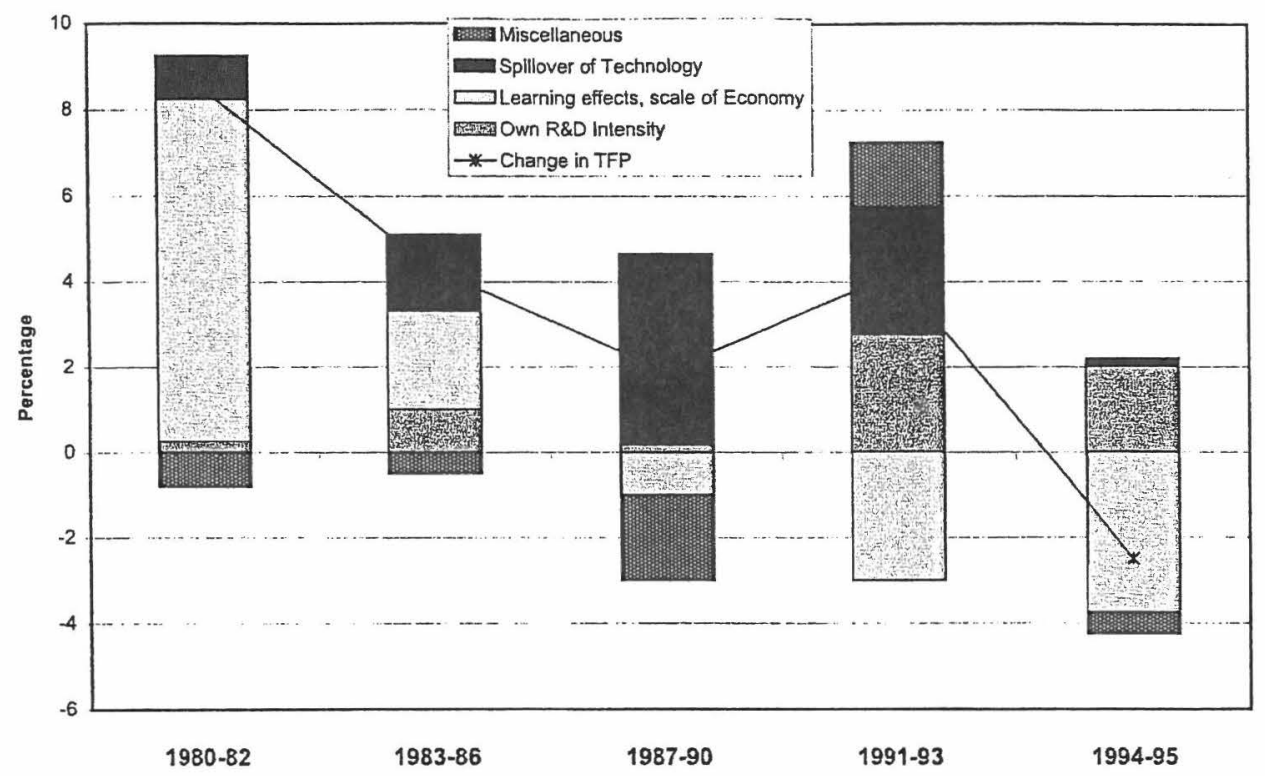

Figure 4 Trends in factors contributing to change in GDP in the Japanese manufacturing industry (1950-1994)

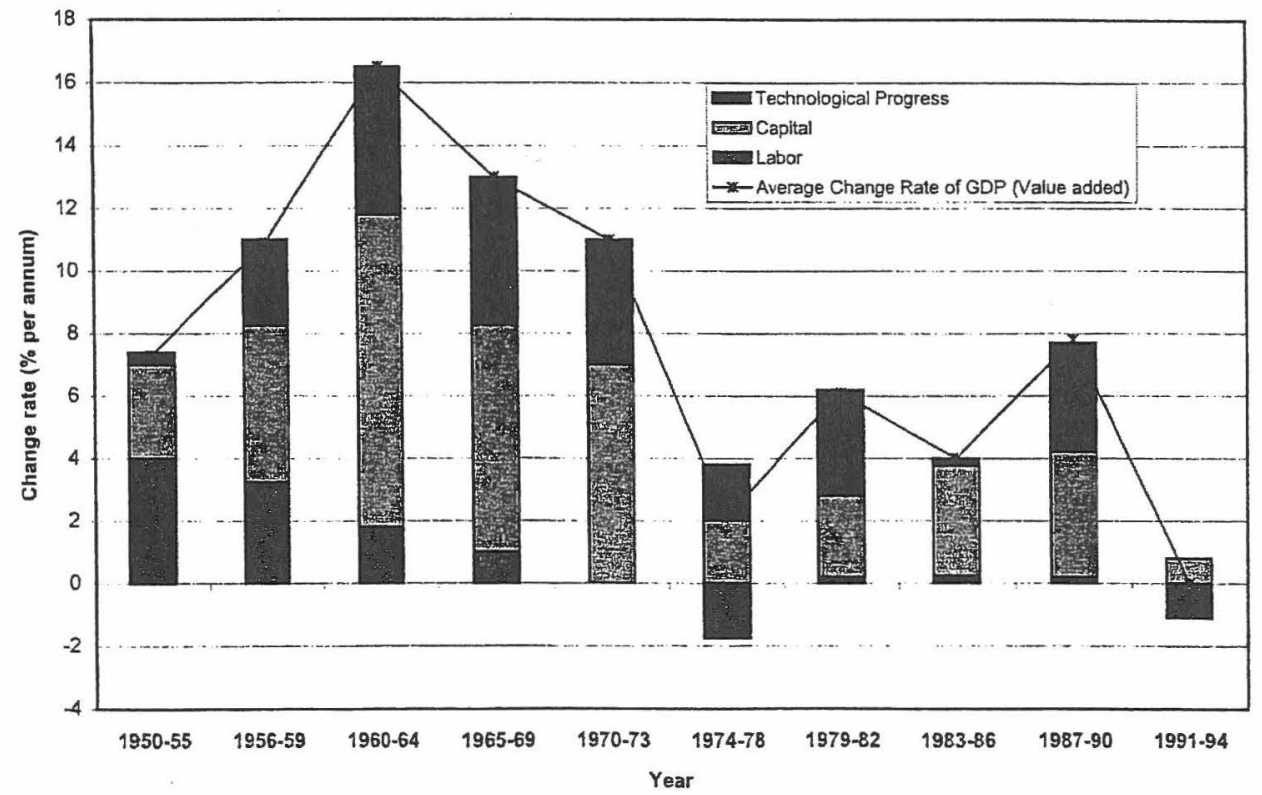


Figure 5 Trends in factors and their magnitude contributing to a change in R\&D investment in the Japanese manufacturing industry

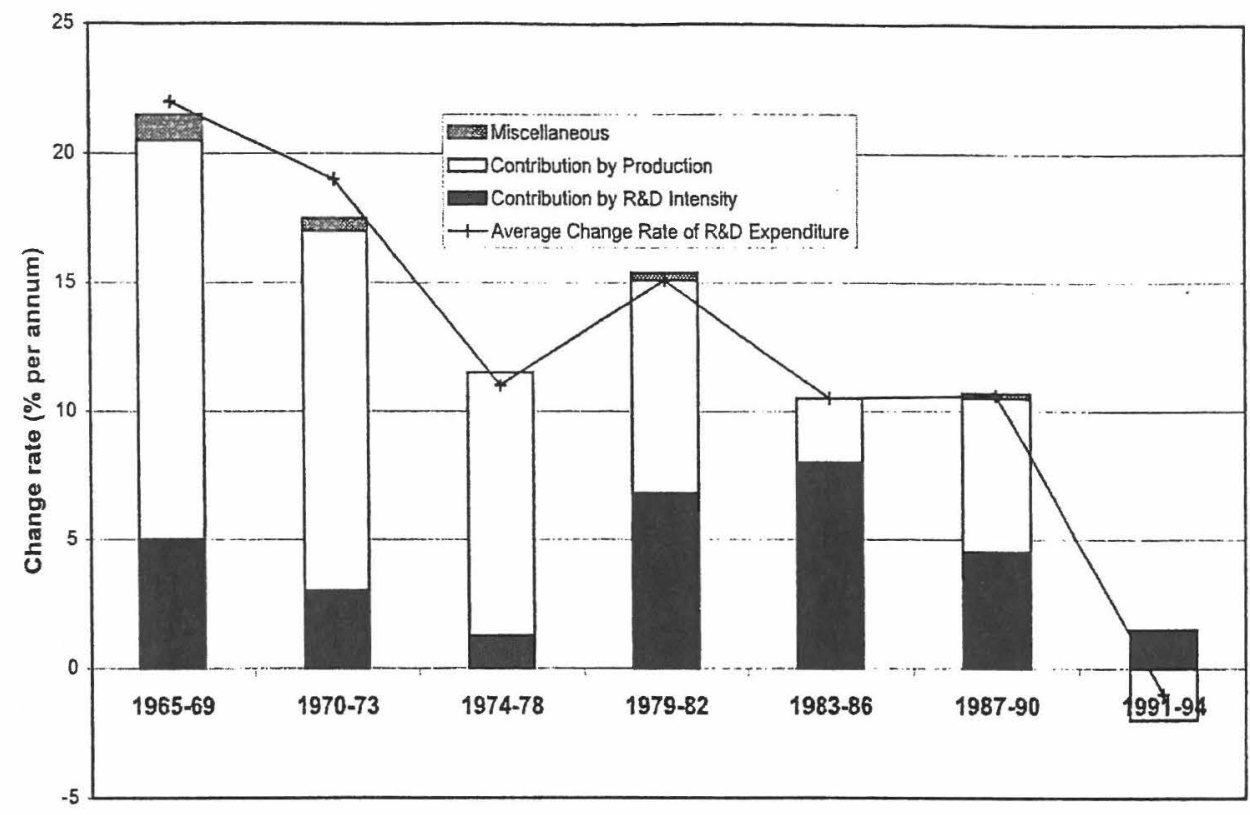

\subsection{Japan's dual economy and its transformation}

The previous analysis has focused on the shift that took place in the late 1980 s and early 1990 s in order to demonstrate that a transition occurred in technology spillovers. Furthermore, the contributing factors to this transition were identified. A closer look at the more recent trends adds to our understanding of the institutional situation in Japan, particularly with respect to the flexibility of labour.

In the process of Japan's post-war recovery and subsequent explosive growth, a gap emerged between SMEs and larger firms in terms of productivity, wages, technology and financing resulting in what is commonly referred to as Japan's 'dual economy.' This theory purports that, in general, Japan's SMEs are weak, due to a number of factors including excessively small firms, lack of diversity amongst the small firms and a less productive use or absence of technology in this critical area. Among reasons for this dual economy was that the Japanese educational system, particularly tertiary education, focused on producing graduates who would be retrained by the larger firms or government offices [23-26] rather than being trained at universities with adaptive skills capable of dealing with changes in the economic environment. This inflexibility is generally evident in a weak SME segment since most graduates are pulled to larger companies.

While this growing inelasticity was evident during the 1980 s with a crescendo in the 1990 s, recent data indicates that some of these factors may be changing. Furthermore, these changes fit with the theory described in this analysis of cyclical rigidity and flexibility. For example, measurements of the size of the Japanese workforce show that 
smaller business establishments are getting larger and that larger enterprises are downsizing (Figure 6). Further evidence indicates that SMEs are getting stronger as companies 'spin off' operations and that SMEs are becoming more stable than their larger counterparts (Figure 7). These trends seem to suggest that Japanese SMEs are becoming more flexible and competitive as they become capable of absorbing labour and technology. However, there still appear to be significant barriers to achieving flexibility in the workforce.

Figure 6 Changes in average workforce size of business establishments

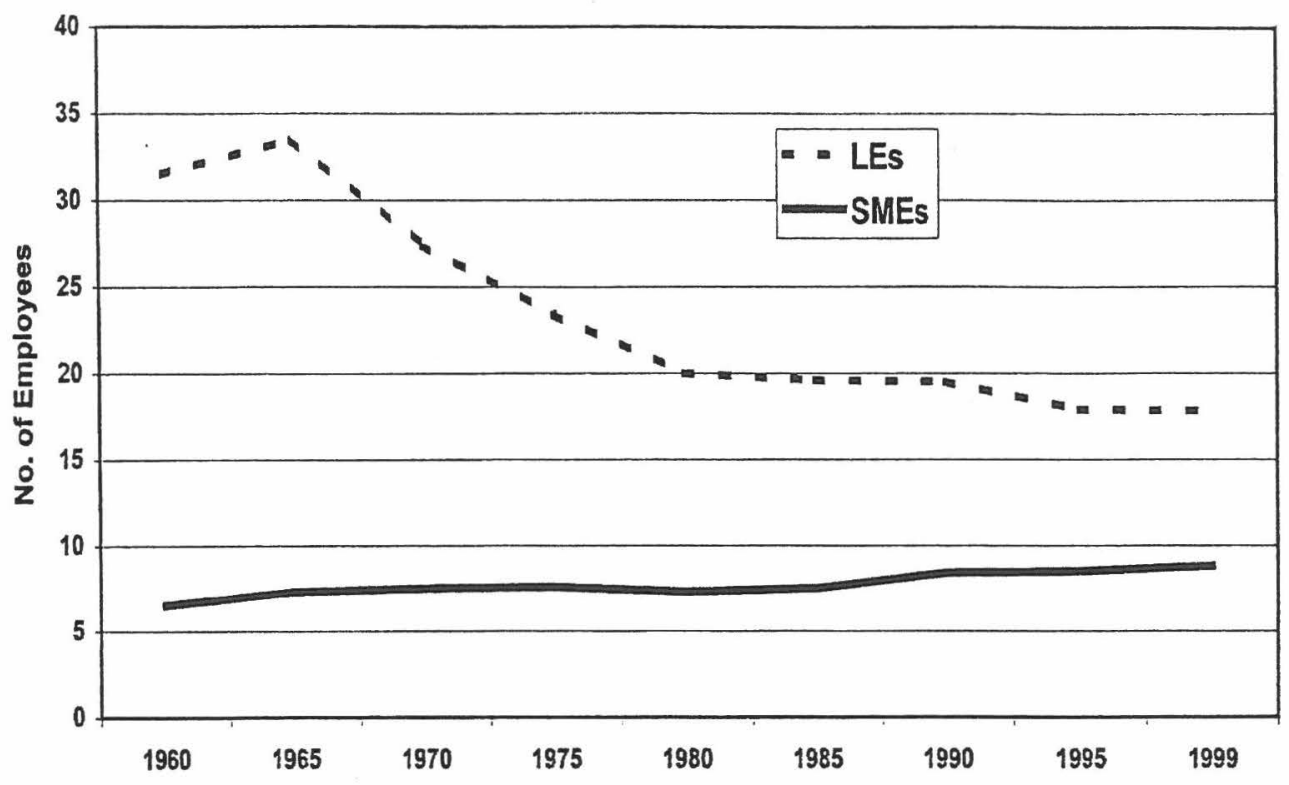

Source: Management and Coordination Agency, Statistics on Business Establishments and Enterprises, Ministry of Finance, Annual Corporate Statistics

1 Employees at SMEs comprise sole proprietors, family employees, paid directors, regular employees and temporary employees

2 Employees at LEs comprise the total average number of paid directors during the period, average number of regular employees during the period, and the average number of temporary employees during the period (dividing the total number of employee hours by average working hours per month)

3 Figures are for calendar years in the case of SMEs and fiscal years in the case of LEs 
Figure 7 Downsizing of business corporations

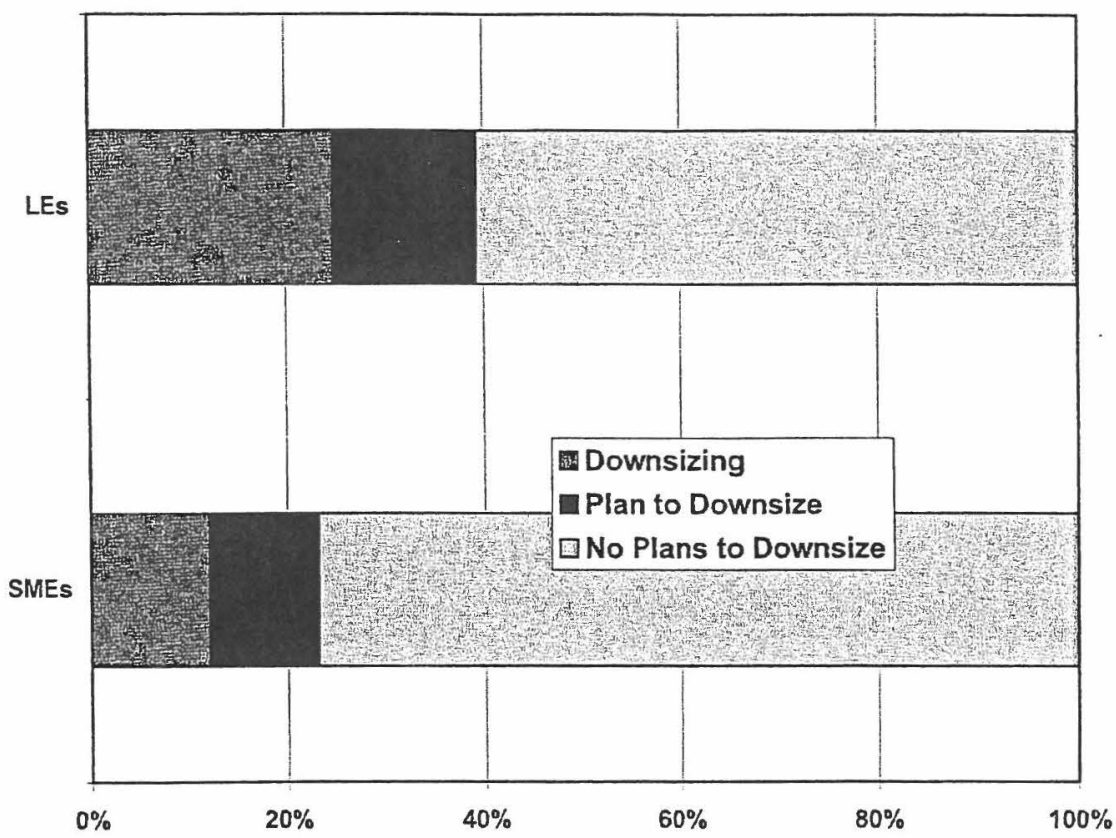

Source: Small and Medium Enterprise Agency, 'Survey of Corporate Management (Corporate Organisation)' (1999)

\subsubsection{Changing lifestyles and institutional flexibility}

Recent data from the Prime Minister's Office National Survey of the Young shows that $33 \%$ of Japanese young adults between the ages of 18-24 have changed jobs, a much smaller proportion than in other countries (Figure 8). This figure suggests that the Japanese labour market is highly inflexible and this is generally thought to be due to the persistence of seniority-based pay and long-term employment practices that both allow and encourage salaried workers hired after graduation from universities to remain at the same firm until retirement. This attitude is slowly changing. A comparison of surveys of attitudes toward changing employment carried out in 1987 and 1999 reveals that the number of people agreeing that 'it is better to work as long as possible at the same company even if dissatisfied' has decreased while those responding that 'it is OK to change jobs if it allows one to make better use of one's abilities' has increased (Figure 9). This change in the labour market offers the growing SME segment of the Japanese economy the opportunity to attract more highly qualified, adaptive personnel. In addition, changing attitudes toward leisure time and a less predictable consumer durables market have shifted priority (Figure 10). The shift in priorities in these areas is forcing institutions to become more flexible in their capacity to meet marketplace demand because the consumer durables market is less predictable. Smaller businesses are ideal for navigating these constraints providing a more flexible atmosphere for workers, accommodating changes in the workforce and responding more quickly to consumer demand. As indicated earlier in Figures 6 and 7, shifts in this direction are occurring. However, obstacles remain. 
Figure 8 International comparison of $\%$ of persons, 18-24 who have changed jobs

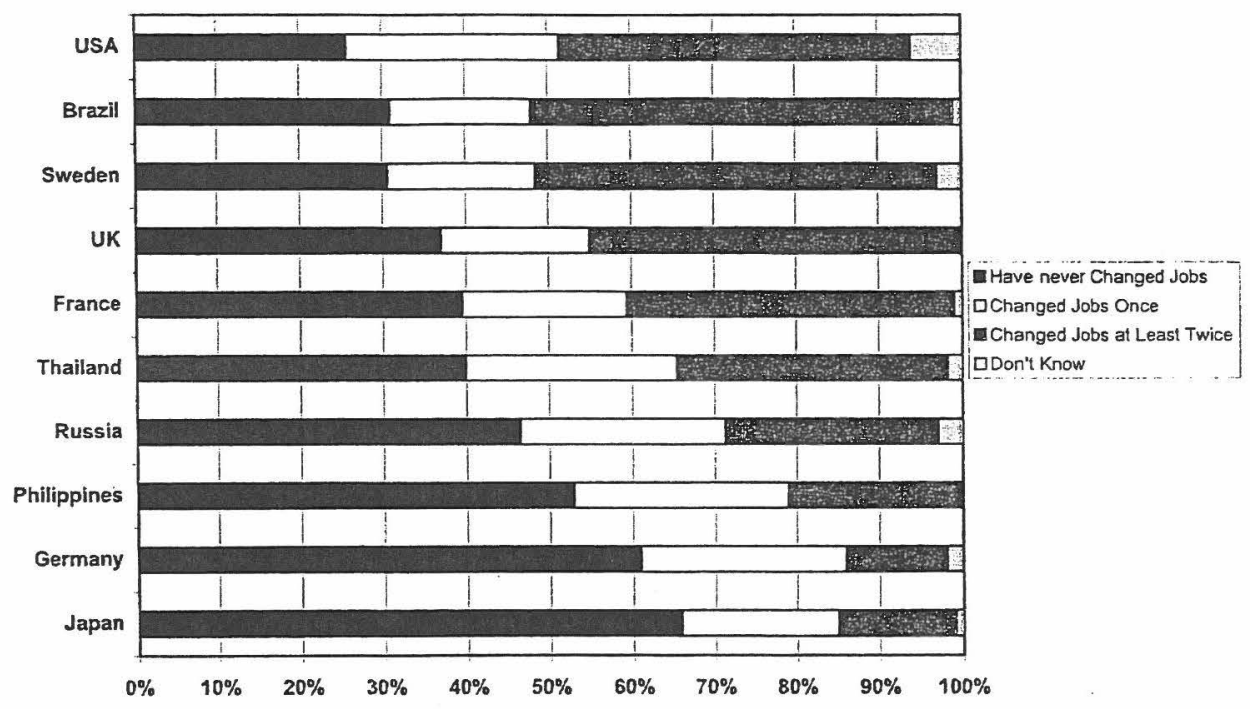

Source: Prime Minister's Office, " 6 th International Opinion Survey of the Young' (1999)

Survey covered persons resident in each of the countries concerned who said they were currently employed

Figure 9 Shifting attitudes toward changing jobs

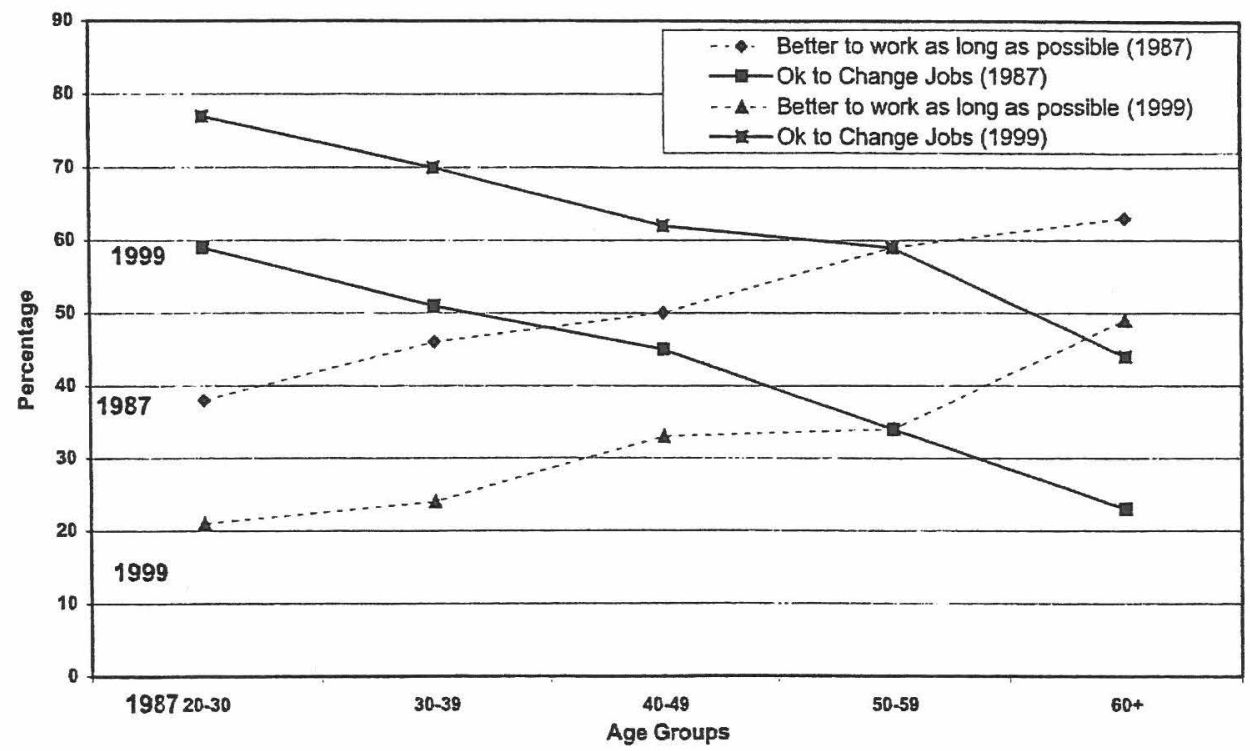

Source: Prime Minister's Office, Survey of Opinions on Work and Life (1987), 'Survey of Opinions on New Modes of Work in the Future' (1999)

Totals do not add up to 100 as data on 'don't knows' etc. are not included 
Figure 10 Changes in lifestyle priorities (1975-1999)

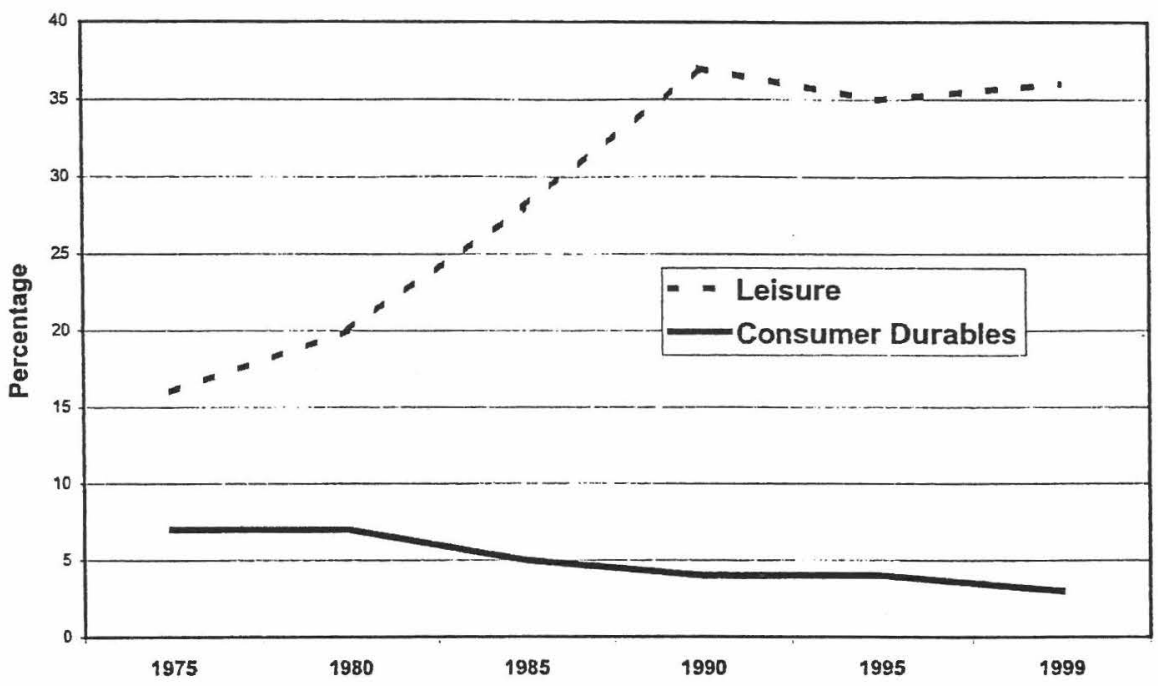

Source: Prime Minister's Office, 'National Lifestyle Opinion Survey' (1999)

1 'Consumer Durables' means the prioritisation of ownership of consumer durables such as cars, electrical products and furniture

2 Figures shown in the graph are rounded to the nearest whole number

\subsubsection{Institutional 'inflexibility' indicated by low IT penetration in SMEs}

Even though there are indications that SMEs are becoming more flexible than their larger counterparts, there is not yet any evidence, which shows that across industries Japan's SMEs are fully taking advantage of their capacity to be more flexible. This is particularly evident when it comes to technology assimilation and R\&D.

In fact, there is some indication that technologically, Japan's SMEs are disadvantaged [9]. Previous studies indicate that there is a strong correlation between company size and IT penetration in Japan. In particular there is a strong correlation between company size and IT expenditure as well as the number of large enterprises in an industrial sector and the level of IT investment per company. The result is that IT penetration in SMEs is very small, further enhancing the 'digital divide' amidst the dual economy of Japan's small and large enterprises.

More recent data support this trend. An examination of the extent of the use of computers at firms by workforce size reveals that a large proportion of SMEs, particularly those with fewer than 20 employees have not yet introduced computers (Figure 11). Use of computers is, however, widespread among SMEs whose profits are growing (Figure 12) indicating that information systems in Japan are just as much a critical success factor as they are elsewhere. Overall, this indicates that institutional flexibility in incorporating IT at the SME level is important but still struggling in Japan. Therefore, Figures 11 and 12 in combination indicate that while institutional flexibility is important, at this point in time it is still lacking in Japan. Is there a pattern where institutions ebb and flow in their flexibility as suggested by Japan's ebb and flow over the last century? Furthermore, how does this ebb and flow 'sync' with other economies? 
Figure 11 State of use of computers in business (by workforce size)

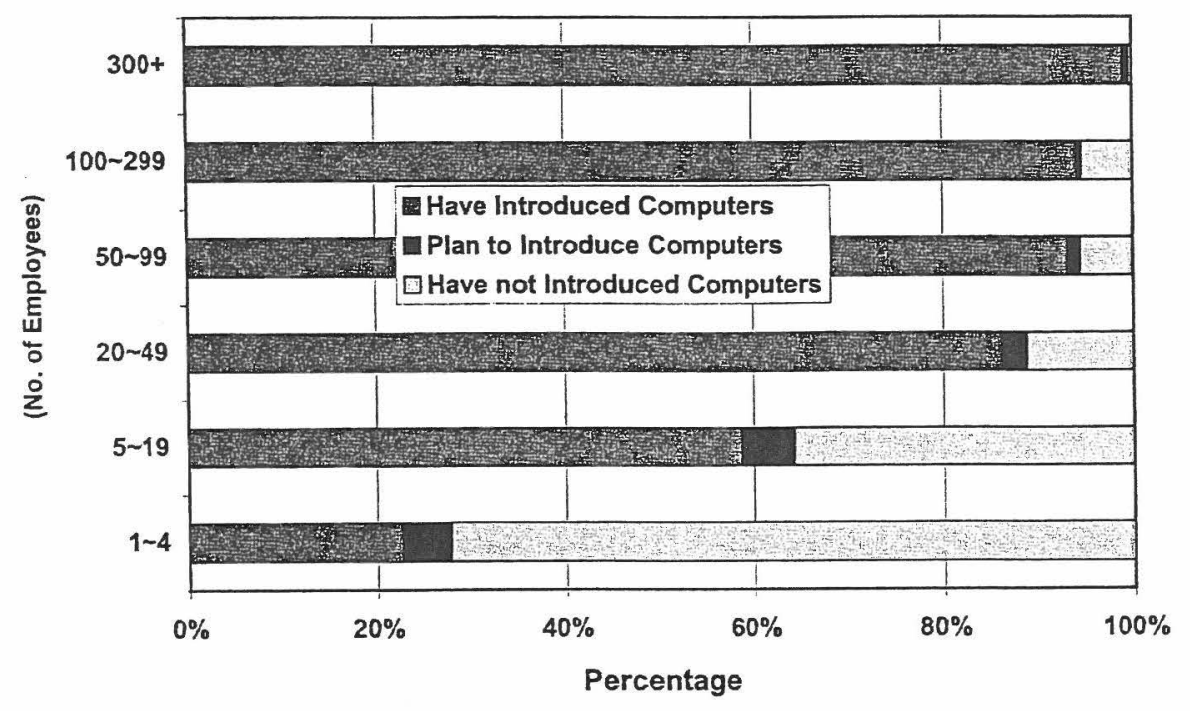

Source: Small and Medium Enterprise Agency, 'Survey of Corporate Management Activities' (1999)

Figure 12 Use of computers and changes in profits (SMEs)

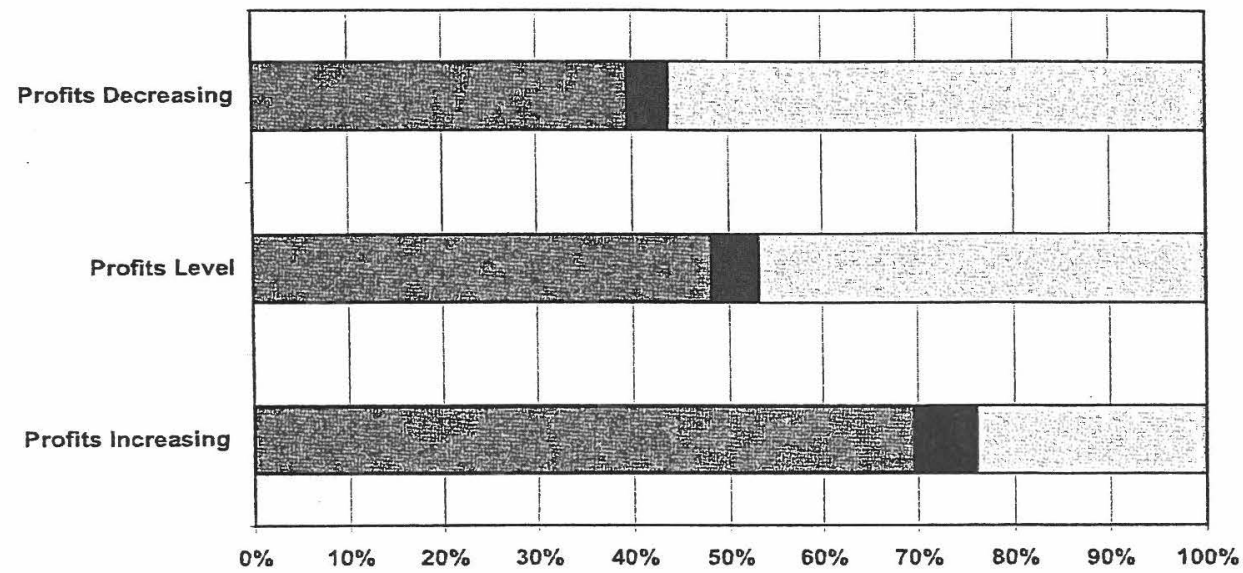

$$
\begin{aligned}
& \text { Have Introduced Computers } \\
& \text { G Plan to Intraduce Computers } \\
& \square \text { Have not Introduced Computers }
\end{aligned}
$$

Source: Small and Medium Enterprise Agency, 'Survey of Corporate Management Activities' (1999)

\section{Contrast between Japan and the USA in the late 1980s and early 1990s}

If we compare the economic growth rate and the factors supporting it in the USA and Japan for the second half of the 1980 s and the first half of the 1990 s it is clearly observed 
that the situation reversed itself dramatically (Figure 13). In the latter part of the 1980s Japan enjoyed the bubble economy and the Japanese manufacturing industry's growth rate was much higher than similar growth in the US manufacturing industry. However, the tables were turned in favour of the USA in the 1990s. Japan's bubble economy burst in 1991 leading to an economic stagnation. Contrary to Japan's stagnation, the US economy started to enjoy growth without inflation. Figure 13 demonstrates this contrast also indicting that the US success from 1992 can largely be attributed to TFP growth. The question is can this growth also be attributed to the institutional flexibility between labour, capital and technology observed in Japan during previous decades?

In order to investigate this, a translog cost function was developed for both the manufacturing industry in the USA and Japan over the last two decades (Table 1). Then a comparative analysis of the substitution mechanism between capital, labour and technology was conducted. The results are summarised in Figure 14. This Figure shows that similar trends can also be observed in such standard sectors as general machinery in both countries. These results indicate that the relationship between capital and labour in both countries was consistently substituted over the whole period. Furthermore, technology and capital were complementary in both countries. While the degree of the complementarity continued to decrease slightly in both countries in the $1980 \mathrm{~s}$, the complementarity in the USA changed to a dramatic increase from the early part of the 1990s as institutions gained flexibility in substituting and trading off factors. In addition, technology and labour were strongly substituted for one another in both countries. While the degree of the substitution continued to decrease slightly in both countries in the 1980 s, substitution in the USA dramatically increased from the early part of the 1990s. These analyses indicate that institutional changes took place in Japan post-war and similarly changes took place in the USA during the 1990s. How do we characterise these changes except to see that there has been some shift in institutional flexibility? Do the institutions and infrastructures converge or diverge?

Figure 13 Balance of economic growth rate and contribution factors in Japan and the US manufacturing industry (1985-1994)

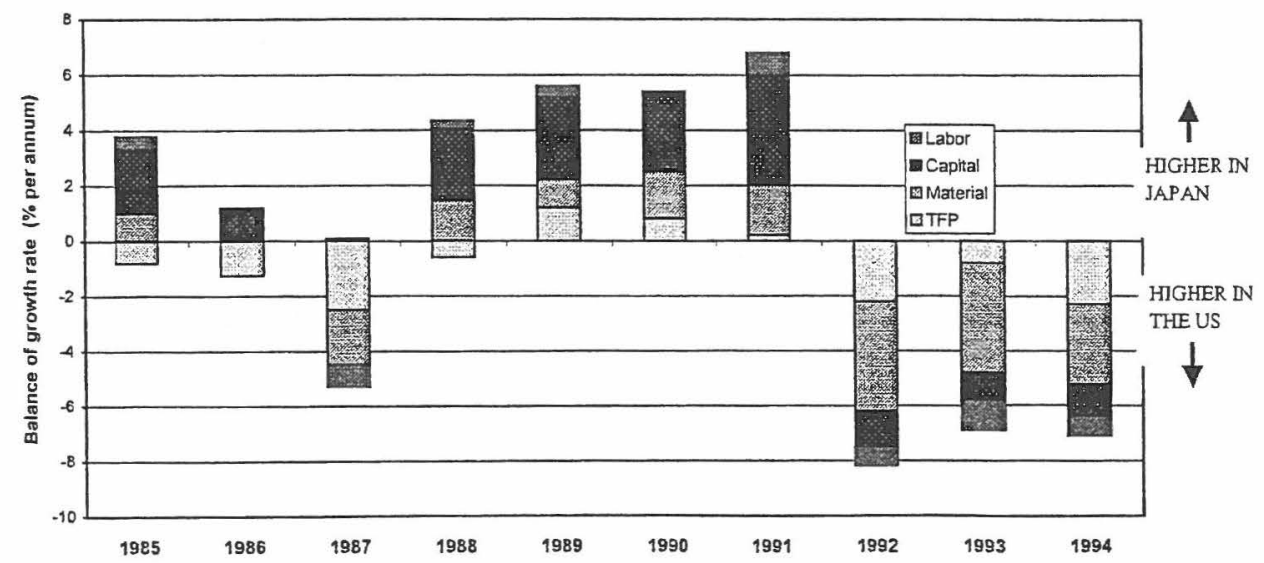

Balance and contributing factors to the balance were measured by estimating the following Cobb-Douglas type production function for both Japanese and US manufacturing industries $Y$ $=A^{\lambda t} L^{\alpha} K^{\beta} M^{\gamma} E^{\delta}$ where Y: production; L: labour; K: capital; M: materials; E: energy;

$\lambda$ : TFP; t: time trend and $\alpha, \beta, \gamma, \delta$ : elasticities 
Table 1 Estimated translog cost function for the Japanese and US manufacturing industries

Japan (1975-1994)

$$
\begin{aligned}
& \mathrm{M}_{1}=0.215+0.497 \log \left(\mathrm{p}_{\mathrm{t}} / \mathrm{p}_{\mathrm{n}}\right)+0.491 \log \left(\mathrm{p}_{\mathrm{t}} / \mathrm{p}_{\mathrm{n}}\right)-0.021 \log \left(\mathrm{p}_{\mathrm{t}} / \mathrm{p}_{\mathrm{n}}\right)+0.142 \log \left(\mathrm{p}_{\mathrm{t}} / \mathrm{p}_{\mathrm{n}}\right) \\
& \begin{array}{llll}
(88.80)(7.74) & (9.71) & (-16.0)
\end{array} \\
& \mathrm{R}^{2}=0.771 \quad \mathrm{DW} 0.44 \\
& \mathrm{M}_{2}=0.146+0.491 \log \left(\mathrm{p}_{\mathrm{t}} / \mathrm{p}_{\mathrm{n}}\right)+0.521 \log \left(\mathrm{p}_{\mathrm{t}} / \mathrm{p}_{\mathrm{n}}\right)-0.327 \log \left(\mathrm{p}_{\mathrm{t}} / \mathrm{p}_{\mathrm{n}}\right)-0.748 \log \left(\mathrm{p}_{\mathrm{t}} / \mathrm{p}_{\mathrm{n}}\right) \\
& \text { (79.10) (9.17) } \\
& \mathrm{R}^{2}=0.770 \quad \text { DW } 0.39 \\
& M_{3}=0.022-0.021 \log \left(p_{t} / p_{n}\right)-0.003 \log \left(p_{t} / p_{n}\right)+0.186 \log \left(p_{t} / p_{n}\right)-0.002\left(p_{t} / p_{n}\right) \\
& \mathrm{R}^{2}=0.952 \quad \mathrm{DW} 0.39 \\
& \mathrm{M}_{4}=0.256+0.142 \log \left(\mathrm{p}_{\mathrm{t}} / \mathrm{p}_{\mathrm{n}}\right)-0.748 \log \left(\mathrm{p}_{\mathrm{t}} / \mathrm{p}_{\mathrm{n}}\right)-0.003\left(\mathrm{p}_{\mathrm{t}} / \mathrm{p}_{\mathrm{n}}\right)+0.086\left(\mathrm{p}_{\mathrm{t}} / \mathrm{p}_{\mathrm{n}}\right) \\
& \text { (11.80) (20.4) } \\
& (-4.94) \\
& (-4.54) \\
& \mathrm{R}^{2}=0.990 \quad \mathrm{DW} 0.69
\end{aligned}
$$

\section{USA (1965 - 1994)}

$$
\begin{aligned}
& \mathrm{M}_{1}=0.174-0.105 \log \left(\mathrm{p}_{\mathrm{t}} / \mathrm{p}_{\mathrm{n}}\right)+0.074 \log \left(\mathrm{p}_{\mathrm{t}} / \mathrm{p}_{\mathrm{n}}\right)-0.004 \log \left(\mathrm{p}_{\mathrm{t}} / \mathrm{p}_{\mathrm{n}}\right)+0.524 \log \left(\mathrm{p}_{\mathrm{t}} / \mathrm{p}_{\mathrm{n}}\right) \\
& \text { (74.90) }(-3.83) \\
& \text { (3.54) } \\
& (-1.52) \\
& (10.20) \\
& \mathrm{R}^{2}=0.748 \quad \mathrm{DW} 0.35 \\
& \mathrm{M}_{2}=0.282+0.742 \log \left(\mathrm{p}_{\mathrm{t}} / \mathrm{p}_{\mathrm{n}}\right)+0.116 \log \left(\mathrm{p}_{\mathrm{t}} / \mathrm{p}_{\mathrm{n}}\right)-0.009 \log \left(\mathrm{p}_{\mathrm{t}} / \mathrm{p}_{\mathrm{n}}\right)-0.032 \log \left(\mathrm{p}_{\mathrm{t}} / \mathrm{p}_{\mathrm{n}}\right) \\
& \text { (13.60) (3.54) } \\
& \mathrm{R}^{2}=0.8201 \quad \text { DW } 0.14 \\
& \mathrm{M}_{3}=0.0189-0.004 \log \left(\mathrm{p}_{\mathrm{t}} / \mathrm{p}_{\mathrm{n}}\right)-0.086 \log \left(\mathrm{p}_{\mathrm{t}} / \mathrm{p}_{\mathrm{n}}\right)+0.013 \log \left(\mathrm{p}_{\mathrm{t}} / \mathrm{p}_{\mathrm{n}}\right)-0.004\left(\mathrm{p}_{\mathrm{t}} / \mathrm{p}_{\mathrm{n}}\right) \\
& \text { (92.50) (-1.52) } \\
& \mathrm{R}^{2}=0.967 \quad \mathrm{DW} 0.79 \\
& \mathrm{M}_{4}=0.028+0.052 \log \left(\mathrm{p}_{\mathrm{t}} / \mathrm{p}_{\mathrm{n}}\right)-0.032 \log \left(\mathrm{p}_{\mathrm{t}} / \mathrm{p}_{\mathrm{n}}\right)-0.004\left(\mathrm{p}_{\mathrm{t}} / \mathrm{p}_{\mathrm{n}}\right)+0.592\left(\mathrm{p}_{\mathrm{t}} / \mathrm{p}_{\mathrm{n}}\right) \\
& \text { (49.40) (10.20) } \\
& (-6.65) \\
& (-6.47)
\end{aligned}
$$


Figure 14 Trends in substitution and complementarity among capital, technology and labour in the Japanese and the US manufacturing industry (1975-1994)
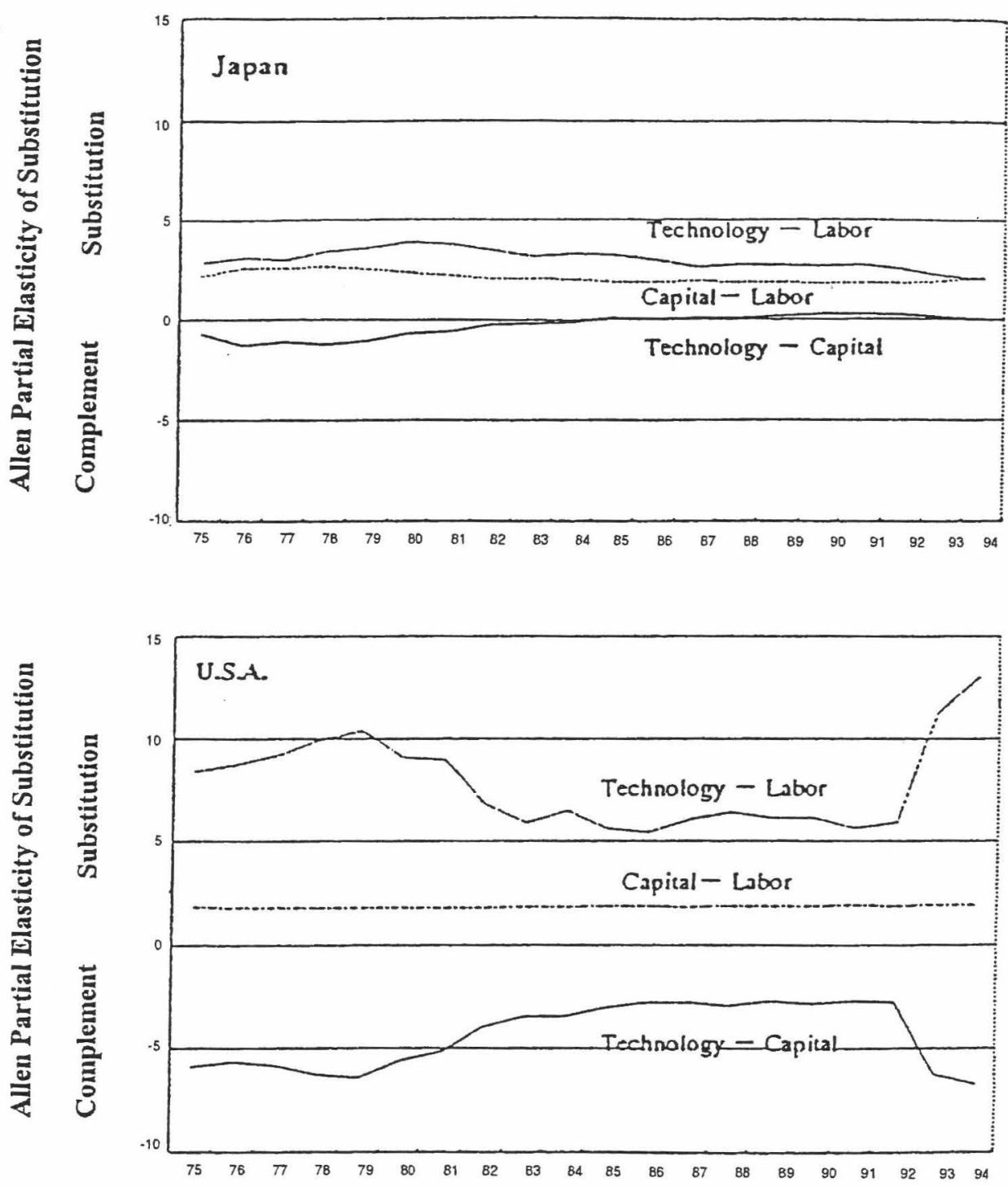

\section{Discussion: convergence and divergence in institutional elasticity}

There seems to be key structural differences in the two economies, but are they converging along different paths institutionally, particularly with respect to the flexibility required in the new global digital economy? Since 1991, organisations in both countries have increasingly invested in and continue to use, internetworking technologies for exchanging e-mail, publishing online information, building intranets and extranets and 
shifting some of their operational systems onto the internet. While Japan has been slower in making these changes amongst its domestic institutions, multinationals which have been doing global business are just as linked to global networks as their US competitors. The difference is in how 'internetworked' companies are within national borders as opposed to between them. While technologists focus on the technological infrastructure necessary to make this transformation possible (e.g. [27]) and economists focus on the relationships between technological investments and organisational, industrial and national performance (e.g. [28]), based on the previous analysis in this investigation demonstrating the differences, these views of a digital economy are not sufficient. While a healthy economy and a dependable infrastructure are critical to ongoing effectiveness, technologies are not just 'click here' interfaces and 'plug and play' standards [27,29] and economies are more than just production functions and transaction costs. Technologies and economies are only meaningful because they are embedded in institutions composed of people in specific social and cultural contexts. Therefore, the complexities analysed in this paper indicate convergence toward institutional flexibility but divergence in the paths taken to reach these elastic institutions. In order to understand these simultaneous processes we will briefly discuss the divergence of infrastructures in Japan and the USA, some of the complexities in the US system which make the seemingly dynamic SME sector appear to be more 'absorptive' to technology spillovers and finally some issues of measurement which need to be clarified in future work.

\subsection{Divergent infrastructures and convergence upon different platforms}

One area of particular strength related to the internet is Japan's growing capabilities in mobile internet services [30]. While PC penetration is lower than in many OECD countries, mobile services are amongst the world's highest [9]. In contrast to the USA, where the digital economy still largely converges around the PC, in Japan the platform of choice for digital convergence is mobile communications. Largely due to Japan's adherence to popular formats such as Wireless Application Protocol and WideBand CDMA, some innovative companies such as Mobilephone Communications International $(\mathrm{MCI})$ are world leaders in developing internet content for digital phones [30]. This content is specifically designed to facilitate transmission and reception of web pages adapted for the smaller screens characteristic of mobile devices. While most content is still geared toward the 'seedier' side of the internet and not yet integrated into the larger, more legitimate business-to-business e-commerce environment, it has tremendous potential in these other e-commerce areas.

Japan clearly outpaces the USA in the standardisation of the mobile phone market. The deregulatory cacophony driving low telecommunications prices and booms in certain economic sectors has tied the technology in the USA to personal computers rather than mobile phones (particularly in business-to-consumer e-commerce). In a sense, a certain rigidity has set in as infrastructure converges on this platform. In contrast, the mobile platform is institutionally more fluid requiring a huge array of spillovers both technologically and in terms of human capital. Some issues related to these technology choices are cultural: Japan is a cash-driven society where credit card use is relatively small. This being the case, different structures for electronic business transactions are established. In the mobile communications market, as in the rest of the telecommunications market, payment for services is usually deducted from a designated bank account with advanced arrangements or paid monthly along with the phone bill. 
This arrangement is significantly different from the US market where the transaction is made at the point-of-sale by credit card. Consequently, the structures in Japan lend themselves more easily to the provision of content driven services (easily facilitated by phone) rather than online purchases (more easily facilitated by PC). The dramatic growth in mobile communications in Japan bodes well for ongoing strengths in this technological area, particularly as mobile phone systems and services advance globally. Therefore, while some institutions remain inflexible, other key areas are emerging with built-in flexibility. Perhaps this is how the transition described in the late 1980s and early 1990s occurred institutionally. However, if SMEs are the 'root' of 'trees' that populate this techno-economic ecosystem, then what is the current state of SMEs in the USA? Are they as flexible as purported by the media or is there evidence of 'solidification' as this analysis might suggest?

\subsection{SMEs in the USA}

New firms in the USA have played a significant role in fomenting innovation in information technology. A recent study by Greenwood and Jovanovic [29] shows that a group of 'IT upstarts' - firms specialising in computer and communications technologies that went public 20 years ago now account for over $4 \%$ of the total US equity market capitalisation. Whilst some of this growth has come at the expense of incumbent information technology firms, the new market value and technology spillovers created by these new businesses appear to be substantial [31]. Surprisingly, more and more research in the USA suggests that there appears to be a very weak relationship between firm size, the tendency to undertake R\&D and the effectiveness of research spending $[32,33]$. That is, in aggregate, small businesses in the USA may not be particularly research-intensive or innovative or open to technology spillovers (very similar to the situation described in Japan). Nonetheless, there is a small sub-group of small businesses in the USA that do appear to excel at innovation, are highly R\&D intensive and consequently very flexible institutionally. These businesses are all venture capital backed start-ups [32]. Therefore, in order to understand policy mechanisms for revitalising technology spillovers, SMEs and institutional elasticity, further investigations should analyse the key problems in financing these firms and the key mechanisms venture investors employ to guide the innovation process. In addition, more policy focus should be placed on ensuring technology and labour flows are healthy.

\section{Conclusions and future work}

This investigation first showed that diversification is the key to flexibility in terms of technology spillovers and that the post-1990s pattern in Japan has been declining. This capacity for technology spillover is linked to institutional gaps, particularly in the ability of the workforce to adjust to new business requirements. A prime example of this is the so-called 'dual economy', which highlights weaknesses in Japan's SMEs. Recent data shows that some of the institutional weaknesses are being rectified as Japan's SMEs grow in strength. However, there exists tremendous labour inflexibility, therefore institutional inflexibility. Workers are very reluctant to change jobs even if dissatisfied and are rarely trained to do so because of seniority and the life-time employment system. However, 
shifts in priorities, particularly in young people, are forcing institutions to become more flexible. The issue of low penetration in SMEs of information technology is also a serious constraint keeping these institutions from filling the required gaps in the economy. This is still a source of institutional inflexibility. A comparison of the USA and Japan demonstrates the shifts in flexibility from the 1980s in Japan to the 1990s in the USA suggesting some institutional 'ebb and flow'. Finally, this work discusses the paradox of both countries converging and diverging institutionally at the same time, pointing out weaknesses and strengths in US SMEs. Measurements required to elucidate this paradox further are also discussed. Further study is required to answer key questions raised in elucidating the relationship between technology spillovers and internetworking, particularly as it impacts on organisational change:

- What kinds of changes are taking place within and across organisations as they internetwork?

- What is the range of work processes associated with interconnecting with customers, workers, partners, suppliers, etc.?

- What kinds of new roles are emerging as organisations become less bounded and more open to external demands and interactions?

Ultimately, this work suggests that policy makers must address technology spillovers as a critical success driver for sustainable strategic advantage. In this regard, tools for measuring and monitoring institutional flexibility in assimilating technology and human capital should be a key focus for enhancing strategic national decisions in technoeconomic development.

\section{References}

1 US Department of Commerce (1999) The Emerging Digital Economy, GPO, Washington DC.

2 Informatization White Paper (1999) Japan Information Processing Development Center (JIPDEC), ISSN 0918-3752, Tokyo Japan.

3 Antonelli, C. (1993) 'The dynamics of technological interrelatedness: the case of information and communication technologies,' in D. Foray and C. Freeman (Eds.), Technology and the Wealth of Nations, St. Martins Press.

4 Jorgenson, D. and Stiroh, K. (1995) 'Computers and growth', Economics of Innovation and New Technology, 3 May, pp.295-316.

5 Shapiro, C. and Varian, H. (1999) 'Information rules: a strategic guide to the network economy', Harvard Business School Press, Boston.

6 Okamoto, Y. (1995) Farewell to Drifting Japan (Saraba Hyouryuu Nihon), Tokyo: Toyo Keizai Shinpousha.

7 Callon, S. (1995) Divided Sun: MITI and the Breakdown of Japanese High-Tech Industrial Policy, 1975-1993, Stanford: Stanford University Press.

8 Hemmert, M. and Oberlander, C. (1998) Technology and Innovation in Japan, Routledge, London and New York.

9 Griffy-Brown, C., Watanabe, C. and Fujisue, K. (1999) 'Technology spillovers and informatization in Japan: an analysis of information technology diffusion in large versus small and medium-sized enterprises', International Journal of Technology Management, Vol. 17, No. 4. 
10 Brynolfsson, E. and Hitt, L. (1995) 'Computers as a factor of production: the role of differences among firms,' Economics of Innovation and Technology, 3 May, pp.183-199.

11 Brynolfsson, E. and Yang, S. (1996) 'Information technology and productivity: a review of the literature,' Advances in Computers, Vol. 43, pp.179-214.

$12 \mathrm{Ng}$, C.Y. (1999)'Socio-economic trends and issues in East Asia,' in C.Y. $\mathrm{Ng}$ and C. Griffy-Brown (Eds.), Trends and Issues in East Asia 1999, Foundation for Advanced Studies in International Development.

13 Button, G. (Ed.) (1993) Technology in Working Order: Studies in Work, Interaction and Technology, London, Routledge.

14 Demchak, C., Friis, C. and La porte, T. (2000) 'Webbing governance: national differences in constructing the face of public organizations,' in G. Garson (Ed.) Handbook of Püblic Information Systems, New York: Marcel Dekker Publishers.

15 Kling, R. and Lamb, R. (1999) 'IT and organizational change in digital economies: a sociotechnical approach', Conference on Understanding the Digital Economy: Data, Tools and Research, 25-26 May, Washington, DC.

16 Economic Planning Agency (2000) 'White paper on the Japanese economy', Economic Survey of Japan.

17 Watanabe, C., Zhu, B., Griffy-Brown, C. and Asgari, B. (2000) 'Global technology spillover and its impact on industry's R\&D strategies,' Technovation, Vol. 20 (in print).

18 Watanabe, C. and Hemmert, M. (1998) 'The interaction between technology and economy: has the 'virtuous cycle' of Japan's technological innovation system collapsed?' in M. Hemmert and C. Oberlander (Eds.), Technology and Innovation in Japan, Routledge, New York, pp.37-57.

19 Watanabe, C. and Nakakuki, M. (1998) 'A comparative analysis of techno-economic development in the United States and Japan focusing on the substitution mechanism of labour, capital and technology,' Proceedings of the Annual Conference of the Japan Society for Science Policy and Research Management, Tokyo, pp.132-137.

20 Wantanabe, C. (1999) 'Systems options for sustainable development - effect and limit of MITI's efforts to substitute technology and energy', Research Policy, Vol. 28, No. 7, pp.719-749.

21 Watanabe, C. and Baba, K. (1998) 'An empirical analysis of the structural relationship between R\&D, its diversification and technology spillovers', Proceedings of the Annual Conference of the Japan Society for Science Policy and Research Management, Tokyo, pp.150-155.

22 Watanabe, C. (2000) 'Visions in co-evolution', The International Workshop on Science and Governance, Brussels.

23 Japan External Trade Organization (JETRO) (1999) 'Japan approves legislation to enhance technology transfer and development', Internal Communication, JETRO.

24 Tsukamoto, Y. (1999) 'A new mission for universities', The Japan Research and Development Center for Metals News, December, Vol. 44.

25 Tsukamoto, Y. (1999) 'The challenge for Tokyo Institute of Technology and the status of the TLO', Internal Presentation, December.

26 Griffy-Brown, C., Watanabe, C. and Katsumoto, M. (2000) 'Japan: overcoming hightechnology failures and restructuring science and technology policy for the twenty-first century', IPTS-ESTO Techno-Economic Analysis Report 1999-2000, The European Science and Technology Observatory and the Institute for Prospective Technology Studies, the European Commission.

27 Shaw, M.J. (1999) 'Electronic commerce: state of the art,' Conference on E-Commerce in the Global Marketplace, 15 April, University of Illlinios, Urbana-Champaign, IL.

28 Brynjolfsson, E. (1993) 'The productivity paradox of information technology: review and assessment,' Communications of the ACM, Vol. 37, No. 12. 
29 Orlikowski, W. (1999) 'The truth is not out there: an enacted view of the digital economy', US National Forum on Ecommerce, May 19.

30 Fulford, B. (2000) 'Highly mobile', Forbes Magazine, 7 February.

31 Greenwood, J. and Jovanovic, B. (1999) 'The IT revolution and the stock market,' American Economic Review Papers and Proceedings, Vol. 89.

32 Kortum, S. and Lerner, J. (1998) 'Does venture capital spur innovation?,' National Bureau of Economic Research Working Paper No. 6846.

33 Lerner, J. (1999) 'Small business, innovation and public policy,' in J. Zoltan (Ed.), Are Small Firms Important?, New York: Kluwer Academic Publishing, in press. 
